\title{
HISTÓRIA DAS BIBLIOTECAS ESCOLARES EM LONDRINA
}

\section{HISTORIA DE LAS BIBLIOTECAS ESCOLARES EN LONDRINA}

\section{RESUMO}

Introdução: O presente artigo tem por objetivo apresentar o histórico das bibliotecas escolares no Município de Londrina, seu desenvolvimento desde sua colonização aos dias atuais.

Objetivo: A pesquisa teve por objetivo descrever e analisar o processo de surgimento das bibliotecas escolares dentro do sistema de ensino e a estruturação de bibliotecas nesses espaços, evolução, conquistas e avanços.

Metodologia: É uma pesquisa de cunho bibliográfico, alicerçada na identificação, leitura e análise de escritas, documentos, leis e decretos, que ocorreram ao longo do tempo neste Município.

Resultados: Aborda o percurso histórico das bibliotecas escolares do Município de Londrina, bem como de sua política de formação de leitores, em especial, por meio do projeto Palavras Andantes.

Conclusões: Esta Instituição, embora atualmente esteja garantida em lei, ainda requer amadurecimento e reflexões mais profundas. Pretende-se com este trabalho apresentar a historiografia das bibliotecas escolares em Londrina e suscitar discussões e contribuições para futuros estudos acerca dessa temática.

Palavras-chave: Biblioteca Escolar. Londrina. Historiografia. 


\section{INTRODUÇÃO}

A presente pesquisa apresenta o percurso histórico das Bibliotecas Escolares no Município de Londrina, desde seu surgimento aos dias atuais. Nas últimas décadas esta instituição foi e está sendo discutida nas áreas diretamente envolvidas com ela, em especial, destacamos a Biblioteconomia e a Educação, visto que as bibliotecas escolares estão dentro das instituições de ensino.

Reconhecido sua importância pela UNESCO desde 2000, essa instituição ainda requer amadurecimento e, principalmente, implantação no sistema de ensino do Brasil, cuja deficiência é grande, conforme demonstra a pesquisa "Avaliação das Bibliotecas Escolares no Brasil”, que 2/3 das 162.819 escolas de educação básica do país não possuem biblioteca.

Em 2010 foi outorgada a Lei № 12.244 que dispõe sobre a universalização da Biblioteca Escolar que deveria, a partir daquela data, acontecer em todas as escolas do país na próxima década. Nesse aspecto, se a lei está vigendo, o mesmo não se pode dizer em relação ao plano efetivo para a construção de bibliotecas nas 108.546 escolas do país (BRASIL, 2011).

Em busca de compreender o processo no âmbito mais local, apresentamos o resultado de uma pesquisa de revisão de literatura acerca do desenvolvimento histórico das bibliotecas escolares no Município de Londrina, desde a colonização da cidade aos dias atuais, evidenciando as conquistas, avanços e peculiaridades.

A pesquisa utilizou-se da revisão bibliográfica, documentos históricos e leis que regeram o município e as bibliotecas ao longo desse processo histórico. Evidencia conquistas e dificuldades que o Município encontrou em toda sua trajetória política para estruturação e legitimação das bibliotecas nas escolas. Apresenta a estruturação e sistematização destes espaços pelo projeto Palavras Andantes, que contempla uma efetiva política de valorização da biblioteca escolar, como espaço de informação, conhecimento, de leitura, de apoio pedagógico aos professores e fruição cultural até a aprovação da Lei 11.535 onde cria o Sistema Municipal de Bibliotecas Livro, Leitura e Literatura - SMBLLL. 


\section{HISTÓRIA DAS BIBLIOTECAS ESCOLARES EM LONDRINA}

Londrina foi criada em 21 de agosto de 1929, com a chegada da Companhia de Terras Norte do Paraná (CTNP), responsável pela colonização da região, porém foi em 1934, mais especificamente no dia 03 de dezembro, pelo decreto no. 2519, que oficialmente, pelo interventor Sr. Manoel Ribas, o Município de Londrina, teve seu primeiro prefeito o ponta-grossense Joaquim Vicente de Castro (BONI, 2004).

A população em 1934 era 1.346 habitantes, já em 1938 teve um grande aumento totalizando em 30.000 moradores na cidade recém-criada. Neste contexto, sente-se a necessidade de oferecer maior infraestrutura à população, como hospitais, postos de saúde, iluminação pública, água encanada, casas comerciais, teatro, escolas etc. (ASARI; TUMA, 1978). A população exigia infraestrutura e, neste mesmo tempo, aumentava o número de crianças com idade a frequentar os bancos escolares, que queriam aprender a ler e escrever.

De acordo com Boni (2004, p. 187)

A primeira escola a funcionar em Londrina foi a escola Alemã do Heimtal, fundada em 26 de julho de 1931, cujo ensino, ministrado pelo professor Richard Blumberg, era em língua alemã. Os imigrantes japoneses foram os responsáveis pela fundação da segunda, a Escola Japonesa, fundada em primeiro de julho de 1933, cujo ensino ministrado era em língua japonesa.

Os japoneses além da escola criada, também criaram e fundaram, em primeiro de julho de 1934, a Sociedade Escolar e Recreativa de Londrina, que mais tarde torna se a ACEL (BONI, 2004). Os alemães caminhando na mesma linha dos japoneses, em 28 de julho de 1934 inauguram a segunda escola alemã de Londrina que situava na "[...] esquina das atuais ruas Mato Grosso e Goiás [...]" (BONI, 2004, p. 188), escola esta, que durante a segunda guerra mundial foi confiscada pelo governo do Paraná e em 29 de outubro de 1945 pelo decreto №. 2233 passa a funcionar como um grupo escolar Evaristo da Veiga. Este colégio Evaristo da Veiga funcionou até meados de 2012 e pela resolução no. 2360 cessa definitivamente suas atividades, de acordo com o processo de municipalização (PARANÁ, 2012b).

De acordo com Cesar (1976, p. 36) foi fundada por um dos pioneiros de Londrina, Heber Palhano, a escola Palhano "[...] na sede de sua propriedade, que se localizava fora das terras da CTNP. Esta escola passou a pertencer à prefeitura de Londrina pela lei ㄲo 8 
de 25/02/48 com a denominação de Escola Duque de Caxias.", porém muito pouco se tem escrito sobre este estabelecimento de Ensino, na Secretaria Municipal de Educação de Londrina não há dados nem de sua extinção e razão pela qual foi extinta (CESAR, 1976).

Em 1936, de acordo com Boni (2004, p. 196), o Instituto Mãe de Deus "[...] começou a funcionar precariamente na cidade e atendia 66 alunos." Londrina, como qualquer outra cidade da época era influenciada pela igreja, as irmãs vinham com uma proposta de educação no estilo europeu, além de ensinar a ler, escrever, ofereciam atividades artísticas, manuais, religiosas, visando à educação integral.

A escola iniciou suas atividades em uma pequena casa de madeira alugada e mantida pela CTNP, logo a Companhia de Terras Norte do Paraná, que doou o terreno para a construção das novas instalações do Instituto Mãe de Deus e em 17 de julho de 1938 foi inaugurado o primeiro bloco da construção do colégio. A cidade crescia e a demanda por vagas na escola também aumentava, em 1947 passava de 400 o número de alunos da escola. Em 1953 o instituto passa a chamar Colégio Mãe de Deus e atende até os dias atuais com os cursos de educação infantil, ensino fundamental e médio, aulas de música e línguas (BONI, 2004). Esta escola no correr dos anos, conforme ampliava sua estrutura física e de ensino, construiu uma biblioteca escolar que hoje se apresenta equipada, com acervo atualizado, que atende às necessidades informacionais de toda comunidade escolar, servindo de apoio e suporte aos professores e toda equipe pedagógica.

A primeira escola estadual de Londrina foi o grupo escolar Hugo Simas, inaugurado em 14 de julho de 1937, com o nome de grupo escolar de Londrina. Em 29 de março de 1962 pelo decreto no 7457 passou a se denominar Grupo Escolar Hugo Simas e torna-se um dos colégios estaduais mais tradicionais da cidade. Em 1976 incorpora o ensino fundamental II e em 1995 implanta-se o segundo grau e passa a chamar Colégio Estadual Hugo Simas que funciona até hoje. O primeiro ano de funcionamento desse colégio foram matriculados 587 alunos devido, à grande demanda e necessidades pela educação. Em 1939 havia 780 alunos matriculados, em 1941, já eram 1.200 alunos (BONI, 2004). Esta escola, na atualidade, conta com uma boa biblioteca, acervo atualizado, rico em literatura brasileira e funciona nos três períodos matutino, vespertino e noturno.

$\mathrm{Na}$ década de 1930, a demanda pelo ensino, por conhecimento, por informação crescia a cada dia, pois aumentava o número da população e as famílias com crianças e 
adolescentes começaram a exigir além do curso primário. Neste contexto, dois sócios, o Dr. Jonas de Faria Castro e Rui Ferraz de Carvalho, construíram um novo estabelecimento de ensino, o Ginásio Londrinense, que além de atender o ensino primário, preparava candidatos ao curso ginasial. De acordo com Boni (2004, p. 210) "[...] a primeira turma do curso ginasial se formou em 1943 [...]", porém em 1944 a sociedade se acabou, quando o estabelecimento de ensino foi adquirido por Zaqueu de Melo, que deu início ao Instituto Filadélfia de Londrina (BONI, 2004).

De acordo com o Boletim do Museu Histórico Pe. Carlos Weiss, (FUNDAÇÃO UNIVERSIDADE ESTADUAL DE LONDRINA, 1980, p. 33), o Instituto Filadélfia de Londrina criou "[...] além do ciclo colegial, a escola técnica e a escola normal." Este Instituto funciona até hoje e ministra ensino em todos os graus e mantém o atual Colégio Londrinense e a Unifil - Universidade Filadélfia, ambos possuem bibliotecas informatizadas no interior de seu espaço.

Quanto ao ensino médio público, de acordo com Cesar (1976, p. 38), "O governo só tomou providências seis anos após a iniciativa particular [...]" , quando criou pelo decreto ํㅜ 336, de 23 de maio de 1945, o Ginásio Estadual de Londrina (CESAR, 1976). Este estabelecimento de ensino, após 14 anos de funcionamento, em 10 de dezembro de 1959, pelo decreto n. 26.950 passa a se chamar Colégio Estadual Professor Vicente Rijo. Em posse de documentos oficiais da escola no Núcleo Regional de Educação de Londrina, analisou-se o regimento escolar desta escola e na seção II dos deveres dos alunos, no artigo XVIII está o seguinte "Zelar e devolver os livros didáticos recebidos e os pertences à biblioteca escolar." (PARANÁ, 2012a). Este é o primeiro documento encontrado, que reporta diretamente às bibliotecas nas escolas, porém não consta nada sobre a data de criação e surgimento da biblioteca na escola.

A seção XIX do mesmo documento retrata os espaços pedagógicos e no artigo 181 está escrito que "A biblioteca é um espaço pedagógico democrático com acervo bibliográfico à disposição de toda comunidade escolar." (PARANÁ, 2012a). Este artigo chama atenção, pois a biblioteca nesta escola além de ser um espaço informacional, é vista como espaço pedagógico, ambiente de aprendizado, de fruição do conhecimento e da cultura, é suporte educacional a alunos, professores e a todos que a frequentam.

O artigo 182, da mesma seção, afirma que "A biblioteca tem regulamento específico, elaborado pela equipe pedagógica e aprovado pelo conselho escolar, no qual consta sua organização e funcionamento." (PARANÁ, 2012a). É uma grande conquista 
para as bibliotecas escolares estaduais, ter garantido no regimento interno da escola a importância do funcionamento deste espaço na escola, sua organização e função como suporte educacional a toda comunidade escolar.

A década de 40, de acordo com Cesar (1976, p. 51):

[...] percebe-se o início da formação de uma rede escolar municipal, ainda muito modesta, mas imposta pela necessidade da própria sociedade. Era necessário dar um mínimo de educação para a população que crescia mais e exigia para seus filhos pelo menos a escola de ler, escrever e contar.

O ensino municipal era uma necessidade para a sociedade da época, Londrina crescia e a população, principalmente a rural, aumentava. A difusão do ensino, da leitura era de fundamental importância para o progresso e desenvolvimento da cidade. De acordo com o Boletim do Museu Histórico nํ 6 (FUNDAÇÃO UNIVERSIDADE ESTADUAL DE LONDRINA, 1980, p. 33), a cidade de Londrina "[...] em dez anos chegou a contar com então expressivo número de 17 unidades escolares, a maior parte na Zona Rural.", devido ao grande número de imigrantes que desbravaram e colonizaram a cidade, porém não há documentos que discorram sobre a existência de bibliotecas nestas escolas.

Candotti (1997, p. 129) afirma que "Desde a fundação de Londrina, a sua população foi predominantemente rural, sendo que, a partir da década de 40 e início de 50, houve uma inversão neste quadro, o que resultou a ampliação acelerada do contingente urbano." Sente-se uma grande necessidade de melhorar a infraestrutura na cidade, além da ampliação das escolas, houve crescimento no comércio, a agricultura tornou-se diversificada, a cidade se destacou na área industrial e foi neste período, que houve a instalação da primeira Biblioteca Pública Municipal de Londrina.

De acordo com o livro, Biblioteca Pública de Londrina: 50 anos no coração da cidade (LONDRINA, 2001, p. 6):

O prefeito Hugo Cabral convoca uma reunião com a chefe de gabinete e diz: Guiomar, isto é muito importante. Você vai chamar o engenheiro, leválo onde é o alistamento militar e pedir para ele trocar o piso, arrumar o que for possível, pintar e preparar o ambiente muito bem. Ali será instalada a primeira Biblioteca Pública de Londrina. Encomende os móveis e faça tudo o que for preciso.

Para a cidade que crescia aceleradamente e se preocupava em oferecer uma boa 
infraestrutura à população, a preocupação com a instalação de uma biblioteca pública era o grande começo da democratização do acesso à informação e à cultura.

A secretária, em resposta ao pedido de Hugo Cabral, fez o solicitado, providenciou o espaço físico, os móveis, as estantes e outra jovem Therezinha de Almeida, futura diretora da Biblioteca, inicia os trabalhos de recuperação e higienização do acervo, que constituía de Literatura Universal, Brasileira, filosofia, obras técnicas e de Monteiro Lobato. A Biblioteca Pública Municipal na realidade foi criada por decreto oㅜ 78 de 23/11/1940, porém somente 11 anos mais tarde é que foi organizada e colocada à disposição da população Londrinense. A primeira diretora foi Therezinha de Almeida Cioffi, que atuou no espaço até 1958 (LONDRINA, 2001).

Ao final de 1958, quando Therezinha deixou a biblioteca havia 4.499 livros, destes de acordo com Coutinho (1959, p. 61) houve durante este ano, as seguintes consultas internas: "generalidades, 1.103; filosofia, 91; religião 5; ciências sociais 377 ; filologia 145; ciências puras 160; ciências aplicadas 133; belas artes, 34; literatura, 211; história e geografia, 853; boletins, 1.199; revistas, 2407 - total de 6.718.” A Biblioteca Pública Municipal atendia a todos que a procurassem, porém havia 1.411 leitores inscritos e que realizavam empréstimos domiciliares (LONDRINA, 2001, p. 13).

Coutinho (1959, p. 61) afirma que na seção circulante os empréstimos em 1958 foram:

Generalidades, 206; Filosofia, 166; Religião, 22; Ciências Aplicadas, 155; Belas Artes, 36; Literatura em Geral, 132; Literatura Americana, 455; Literatura Inglesa, 892; Literatura Alemã, 87; Literatura Francesa, 778; Literatura Italiana, 63; Literatura Espanhola, 18; Literatura Portuguesa, 98; Literatura Brasileira, 746; Literatura em outras línguas, 120; História e Geografia, 447; Boletins, 16; Revistas, 224; Livros Infantis, 1038; Total: 6.352 .

Ao analisar a estatística de empréstimo de livros no ano de 1958, pela Biblioteca Pública Municipal de Londrina, destaca-se o número de empréstimo de literatura infantil, que se sobressai a todos os outros gêneros, o que vem mostrar a necessidade de haver uma biblioteca em cada escola, para atender as necessidades de leitura das crianças, adolescentes e também dos professores que utilizariam o acervo como recurso informacional e suporte nos planejamentos de aulas, projetos e atividades.

$\mathrm{Na}$ década de 50 e 60 do século XX, o Município de Londrina enfrenta uma grande crise no desenvolvimento do ensino. Houve um crescimento acelerado da população 
urbana, aumentou a demanda por vagas nas escolas. Dentro deste contexto, faltavam escolas e professores capacitados, aliados à falta de definição dos órgãos governamentais responsáveis pela Rede de Ensino. Governo estadual e governo municipal não se definiam frente às responsabilidades da educação na cidade, o que gerou inúmeras reclamações na Câmara Municipal (CESAR, 1976). Diante da polêmica dificuldade que Londrina enfrentava, com falta de escolas e instalações adequadas para as que existiam, constata-se que as bibliotecas escolares naquele período ainda estavam longe de se tornarem presentes dentro das escolas públicas do Município.

A preocupação maior era com ensino, formar professores, para formar alunos. Foi neste período que aconteceu a primeira Semana Educacional em nossa cidade, envolvendo professores que atuavam nos segmentos públicos e privados. Em análise dos documentos da DEPAS - Antigo departamento de Educação e Assistência Social, as escolas para atingirem seus objetivos iniciaram a criação de laboratórios, museus, bibliotecas, hortas e de acordo com Cesar (1976) afirmava-se que "[...] se o professor for dedicado e inteligente saberá dar o valor preciso a este auxiliar - o museu, a biblioteca, a farmácia, o jornal, os diários, os livros de ata e controle, a horta, etc."

As reuniões pedagógicas se tornaram frequentes, a Rede Municipal de Ensino acompanhou a evolução do Estado e o sistema de ensino em Londrina ao final da década de 60 passou da fase de implantação para a fase de consolidação. (CESAR, 1976), porém nesta fase de consolidação do ensino, não há menções à implantação e estruturação das bibliotecas escolares, sabe-se que eram utilizadas para auxiliar o professor, mas não há nada documentado sobre o espaço físico, composição do acervo, móveis, profissional que atuava na biblioteca.

A cidade continuava crescendo e exigia da administração um novo posicionamento para atender as necessidades da população, o que gerou uma reforma administrativa na Prefeitura. Com esta medida, criam-se várias secretarias e entre elas a Secretaria Municipal de Educação e Cultura, pela Lei Municipal no 1.578 de 11/11/1969 e que gerou dois departamentos, o Departamento de Educação e Departamento de Cultura (CESAR, 1976).

A nova Secretaria de Educação e Cultura sentia a necessidade de ajustar a estrutura educacional do Município e contratou uma equipe especializada para tal função, o que originou o Projeto denominado Sócio Pedagógico, que não foi colocado inteiramente em prática, por falta de interação entre os planejadores, educadores e a 
realidade educacional da cidade. $\mathrm{O}$ projeto era muito arrojado, além das expectativas, difícil de ser colocado em prática, porém foi este projeto que motivou mudanças e impulsionou o chamado "mutirão da educação", unindo forças da Prefeitura, população, governo de Estado e união o que gerou um grande aumento na Rede Escolar, possibilitando maior atendimento à população.

Em 1970 já havia 137 escolas municipais com 13.002 alunos matriculados e 15.000 vagas disponíveis, porém não há dados de quantas escolas possuíam bibliotecas neste período (CESAR, 1976).

Não há nenhum item do projeto Sócio Pedagógico que mencione algo acerca das bibliotecas nas escolas, porém no item 3.3 dos objetivos do projeto são consideradas as recomendações das Conferências Internacionais de Instrução Pública (publicação do MEC-INEP, Brasil, 1965) ํo 8, e no subitem 11 diz que "[...] a ação da escola se complete com a criação de instituições pré-escolares ou pós-escolares, tais como: círculo de jovens lavradores, bibliotecas itinerantes, missões pedagógicas e culturais." (LONDRINA, 1969, p. 5). Este é o único item do projeto que reporta à biblioteca, visto que a criação de uma biblioteca em cada escola era uma dificuldade no momento, pois até escolas faltavam, a ideia era criar uma biblioteca itinerante que fosse até as escolas com livros, revistas para suprir um pouco das necessidades informacionais dos alunos e professores.

Em análise do documento: Aspectos históricos, físicos, econômicos e institucionais do Município de Londrina: documento consulta, nota-se que em 1978, havia no Município de Londrina:

- 24 Escolas Municipais na área urbana de Londrina;

- 31 Escolas Municipais na área rural de Londrina;

- 07 Escolas Municipais no Distrito da Warta;

- 15 Escolas Municipais no Distrito de Irerê;

- 08 Escolas Municipais no Distrito de São Luiz;

- 09 Escolas Municipais no Distrito de Paiquerê;

- 15 Escolas Municipais no Distrito de Guaravera;

- 29 Escolas Municipais no Distrito de Lerroville;

- 26 Escolas Municipais no Distrito de Tamarana;

- 35 Escolas Estaduais na área urbana de Londrina;

- 01 Escola Estadual no Patrimônio Selva;

- 01 Escola Estadual no Patrimônio Espirito Santo;

- 02 Escolas Estaduais no Distrito da Warta;

- 03 Escolas Estaduais no Distrito de Irerê;

- 02 Escolas Estaduais no Distrito de São Luiz; 
- 02 Escolas Estaduais no Distrito de Paiquerê;

- 02 Escolas Estaduais no Distrito de Guaravera;

- 03 Escolas Estaduais no Distrito de Tamarana;

- 19 Escolas Particulares;

- 18 Jardins de Infância.

Totalizando 164 escolas municipais, 51 escolas estaduais, 19 escolas particulares e 18 jardins de Infância, totalizando 252 estabelecimentos de Ensino (ASARI; TUMA, 1978), porém no documento analisado não há menção a bibliotecas nas escolas. Sabe-se que os colégios particulares eram providos de uma boa estrutura física, equipamentos, móveis e bibliotecas, mas nas Escolas Municipais e Estaduais a implantação foi um pouco mais demorada e contava apenas com a biblioteca itinerante, chamada de biblioteca ambulante que ia até as escolas do Município.

A biblioteca ambulante fazia sucesso entre professores e equipe educacional, pois "[...] além da biblioteca da divisão, existia uma biblioteca-ambulante para atendimento ao professor da Zona Rural. A distribuição de livros era feita por ocasião das visitas das orientadoras e supervisoras com objetivo de incentivar o professor à leitura." (LONDRINA, 1971, p. 18). A preocupação neste momento era com a formação de um professor leitor, crítico e atuante, que pudesse contribuir para formação integral de seus alunos. Esta biblioteca era coordenada pela Biblioteca Pública Municipal de Londrina.

Durante as décadas de 70 e 80 começaram a surgir as bibliotecas sucursais, ou seja, eram bibliotecas escolares, que situavam dentro das Escolas Municipais, porém eram administradas pela Biblioteca Pública Municipal de Londrina. De acordo com o documento Biblioteca Pública de Londrina: 50 anos no coração da cidade, (LONDRINA, 2001, p. 18) "A primeira foi organizada na Escola Municipal Carlos Kremer, na Vila Casoni." De acordo com Silva, (2006b, p. 60) neste período "[...] objetivava-se descentralizar o atendimento do centro da cidade e levá-lo aos estudantes do bairro. A partir de então, são criadas as salas de leitura ou bibliotecas sucursais, como eram chamadas as bibliotecas escolares." Aos poucos estas bibliotecas foram aumentando e a biblioteca ambulante que até então ia até os espaços educacionais para suprir as necessidades informacionais dos professores e aluno, foi gradativamente desativada (LONDRINA, 2001, p. 19).

Na década de 80, mais especificamente no dia 10 de dezembro de 1984, é criada e inaugurada a Biblioteca Pública Infantil de Londrina. O acervo desta biblioteca foi composto por obras de literatura infantil e infantojuvenil, obras didáticas, periódicos, gibis 
e pastas com datas comemorativas e assuntos diversos, totalizando 11.000 (onze mil) volumes. De acordo o histórico da biblioteca disponível no site da prefeitura de Londrina, "[...] com atividades culturais e recreativas tem por objetivo despertar e incentivar o hábito de leitura, estimular a cultura o lazer e a arte, dinamizar o uso do livro e da biblioteca e promover a integração da biblioteca com a comunidade." (LONDRINA, 2013a).

Essa biblioteca está situada na Avenida Rio de Janeiro № 413, anexa à Biblioteca Pública e desenvolve várias programações durante o ano, como: Programação de férias nos meses de janeiro e julho, Semana do Monteiro Lobato, Festa Junina focando nos causos e brincadeiras caipiras, Semana da Criança, Dia da consciência negra, Murais e Painéis temáticos focando nas datas comemorativas. Durante esses eventos, várias atividades são desenvolvidas, como: exposições, oficinas de dobraduras, contações de histórias, rodas literárias, jogos dramáticos e de raciocínios, exibição de filmes, soletrando palavras, brincadeiras cantadas e até piquenique com palavras. A Biblioteca Infantil de Londrina, no ano de 2012, atendeu 1.818 crianças com estes projetos, realizou 239 cadastros para novos leitores e realizou 7.303 empréstimos de livros (LONDRINA, 2013a).

A década de 90 é encerrada com 56 bibliotecas escolares ou sucursais, espalhadas pelos bairros de Londrina. Nestas bibliotecas, de janeiro a julho de 2001, realizaram 68.908 atendimentos ao público; 23.368 empréstimos de livros; possuíam 14.081 livros cadastrados e o acervo total era composto de 140.499 títulos (LONDRINA, 2001). Embora sejam números expressivos, nesta época as bibliotecas das escolas eram vistas por muitos, como lugar de castigo, as instalações físicas não eram as melhores e os profissionais que atuavam geralmente eram professores e estes não recebiam capacitação voltada para atuação, como mediadores da leitura, do livro e da literatura. A biblioteca não estava inserida no contexto pedagógico da escola e não atuava ativamente na promoção da leitura.

Segundo Silva (2006a, p. 69): "Mediar a leitura na escola tornou-se nas últimas décadas umas das premissas fundamentais para o desenvolvimento da educação no Brasil.", pois a leitura é essencial para o desenvolvimento do ser humano, ela forma e transforma. Mediar a leitura dentro da biblioteca por um profissional capacitado para tal função é imprescindível para uma cidade em constante crescimento como Londrina. Formar leitores é formar cidadãos críticos, reflexivos, atuantes, ativos na comunidade em que estão inseridos, é formar uma nova sociedade. 
De acordo com Silva (2006a, p. 69):

Em 2000, aproximadamente 2/3 das escolas da Rede Municipal de Ensino de Londrina possuíam, no ensino fundamental, um professor que contava histórias para as turmas, além de realizar empréstimos e, em alguns casos, pesquisa nas chamadas salas de leitura ou biblioteca da escola. E esse professor, em sua grande maioria composta pela população feminina, era denominado Professor da Hora do Conto.

Esse dado Silva (2006a) obteve através de uma pesquisa que realizou durante o ano de 2000, sobre a leitura literária e sua utilização pelo professor da Hora do Conto no Município de Londrina. A pesquisa traz todos os desafios enfrentados pelos mediadores de leitura da Rede Municipal de Londrina, bem como as dificuldades quanto aos procedimentos pedagógicos e também quanto ao acompanhamento realizado nas bibliotecas das escolas, ora pela Secretaria Municipal de Educação (SME), ora pela Secretaria Municipal de Cultura (SMC).

A realidade constatada pelo pesquisador, não era das melhores e de acordo com Silva (2006a, p. 74):

Embora a hora do conto fosse uma prática cotidiana em muitas escolas da rede municipal de Londrina, nem sempre ela era continua, ou seja, não havia planejamento e procedimento comuns a todas as escolas. Cada unidade escolar, à sua maneira, a desenvolvia do modo que entendia.

Os professores que atuavam na biblioteca recebiam na época uma formação mensal, oferecida pela Secretaria Municipal de Cultura, através da Biblioteca Pública Municipal Parigot de Souza, porém não havia uma proposta sistematizada de formação para os professores atuarem como contadores de histórias e mediadores de leitura nas bibliotecas das escolas. A formação era técnica e os professores que atuavam nas bibliotecas tinham muitas dúvidas quanto ao seu papel e sua importância dentro do espaço escolar. Na realidade faltava uma proposta estruturada que envolvesse toda Rede Municipal (SILVA, 2006a).

Neste contexto, a pesquisa realizada por Silva resultou na estruturação de uma proposta de implantação de um projeto de leitura voltada a toda Rede Municipal de Ensino de Londrina. Silva defendeu a necessidade de uma reestruturação das formações que os professores/mediadores vinham recebendo até então, e apresentou a Secretaria Municipal de Educação no ano de 2002, um novo projeto de Leitura para o Município de 
Londrina, o projeto "Programa de Formação do Professor da Hora do Conto e Auxiliar de Biblioteca da Rede Municipal de Londrina”. A Secretaria Municipal de Educação já buscava estratégia para a criação de um projeto voltado à leitura e seleção de livros para as escolas, o que veio ao encontro com a pesquisa e proposta de Silva (SILVA, 2010).

O projeto foi aprovado pela S.M.E e se chamou "Biblioteca Escolar: Palavras Andantes" e de acordo com Silva (2010, p. 72-73):

Os objetivos específicos estabelecidos foram: Oportunizar ao professor a reflexão sobre sua prática de estímulo à leitura em sua comunidade escolar; Promover encontros mensais de estudo sobre a leitura, a literatura, a criança e a biblioteca escolar; Sistematizar procedimentos serem empregados na biblioteca escolar e hora do conto, visando a transformar a biblioteca escolar em espaço cultural da comunidade à qual pertence; Fomentar a disseminação da leitura, em especial, a literária; Incentivar a utilização da biblioteca escolar como centro informacional para a escola e para a comunidade; Promover a instalação de espaço de leitura nas escolas que ainda não o possuam; Visitar e assessorar pedagogicamente as bibliotecas escolares; Trabalhar em parceria com a Biblioteca Pública Municipal para o processamento técnico do acervo.

O projeto de Silva, aprovado em 2002, foi o primeiro documento do Município de Londrina, que contempla uma efetiva política de valorização da biblioteca escolar, como espaço de informação, conhecimento, de leitura, de apoio pedagógico aos professores, de fruição cultural. $O$ documento valorizou e sistematizou uma capacitação contínua do profissional mediador de leitura, fomentando a leitura literária e sua disseminação a toda comunidade escolar, além de inserir a Biblioteca no contexto pedagógico da escola.

Silva, durante a execução do projeto, avaliava constantemente suas metas, baseando-se nos relatos dos que atuavam na biblioteca da escola, muitas vezes angustiados por sentirem desvalorizados no espaço escolar. Diante disso, Silva priorizou em seu calendário de formação, cursos para os professores/mediadores de leitura, que vinham ao encontro das necessidades mais urgentes, ou seja, assuntos relativos às atividades cotidianas da biblioteca escolar, também estabeleceu diretrizes para 0 desenvolvimento do processo técnico do acervo junto a Biblioteca Pública Municipal (B.P.M), com a criação do documento "Normas para o Processamento do Acervo das Bibliotecas Escolares." (SILVA, 2010, p. 77-80).

Era a primeira vez na história de Londrina, que se via um projeto tão bem estruturado, que seguia todas diretrizes das esferas governamentais. O projeto "Biblioteca Escolar: Palavras Andantes" foi pioneiro no Paraná, o primeiro em todo Estado a se 
preocupar com a efetiva ação da biblioteca na escola e dos professores que nelas atuavam, seguido da nossa capital que três anos depois em 2005, após a criação da Lei no 10.753 de 30 de outubro de 2003 conhecida como a Lei do Livro, é que criou o sistema de Bibliotecas Escolares de Curitiba (BRASIL, 2003).

Neste período havia 79 escolas em Londrina e todas tinham uma biblioteca ou espaço com armários e livros, mesmo que fossem no pátio da escola, porém de acordo com Silva (2010, p. 84) o que existia era "[...] um ambiente nada pedagógico, pois a leitura para o aluno, nesse caso, estava associada a algo nada bonito e organizada, como deve ser o aprendizado.", algumas bibliotecas pareciam depósitos de livros e materiais, a mobília não ofereciam segurança e estabilidade à criança. Silva (2010, p. 88) afirma que "[...] havia a necessidade de provocar a reflexão sobre a importância do ambiente pedagógico da biblioteca no âmbito da educação da criança." o que tornou fundamental adaptar uma proposta a respeito do espaço e edifício da biblioteca para que as escolas tivessem consciência de sua importância e contribuição para o desenvolvimento e formação das crianças (SILVA, 2010).

Diante do exposto, viu-se a necessidade de estabelecer parâmetros para que houvesse uniformidade nos procedimentos internos das bibliotecas da Rede Municipal de Londrina. Foi aí que em dezembro de 2002, estava pronta a "Proposta Pedagógica da Biblioteca Escolar" do Município de Londrina com premissas que assegurassem a continuidade e sistematização do projeto (SILVA, 2010). A cada dia e a cada ano, o projeto ganhava força, respeito e reconhecimento não só na rede, mas em toda cidade, por ser um projeto que formava professores e transformava a realidade das bibliotecas das escolas e de suas práticas nesses espaços.

As bibliotecas escolares do Município de Londrina durante todos esses anos eram valorizadas e reconhecidas como espaço pedagógico, onde teoria e prática caminhavam de mãos dadas, o que resultou em 2008 em um prêmio Nacional "O prêmio Viva Leitura". Este prêmio faz parte do Plano Nacional do Livro e da Leitura e o objetivo é estimular, fomentar e reconhecer boas práticas de leitura, com o foco em transformar nosso país num país de leitores (BRASIL, 2008). O projeto Biblioteca Escolar: Palavras Andantes do Município de Londrina - Paraná foi o vencedor da categoria 2 - Escolas Públicas e Privadas e esse prêmio vem confirmar e valorizar o projeto como ação efetiva em nosso Município e que atua como Politica Pública da Leitura. O projeto está ativo, defendendo e lutando para manter tudo o que foi conquistado. 
Em 9 de abril de 2012, a Câmara Municipal de Londrina aprovou a Lei № 11.535, que dispõe sobre o Sistema Municipal de Cultura de Londrina, seus princípios, objetivos, estrutura, organização, gestão, inter-relações etc. e na subseção II desta Lei, discorre sobre a criação, implantação, composição e funcionamento do Sistema Municipal de Bibliotecas, Livro, Leitura e Literatura - SMBLLL, e nos artigos 69 ao 75, é reportado especificamente para os objetivos, criação, composição e gestão do Sistema Municipal de Bibliotecas, Livro, Leitura e Literatura, conforme segue abaixo são:

Art. 69. Consideram-se objetivos gerais do Sistema Municipal de Bibliotecas, Livro, Leitura e Literatura: I - a democratização do acesso, garantindo privilégio de apoio às bibliotecas de acesso público; II - o fomento à leitura e à formação de mediadores, atuando na necessidade de fomentadores que ajudam a criar novos leitores; III - a valorização da leitura e da comunicação, trabalhando o livro como valor social e cultural e como bem público a se preservar como direito de cidadania; IV - o desenvolvimento da economia do livro; $\mathrm{V}$ - o fomento à publicação de autores locais; VI - o incentivo à criação literária, oficinas, produção e circulação.

Art. 70. O Sistema Municipal de Bibliotecas, Livro, Leitura e Literatura SMBLLL será composto pelos segmentos atuantes na área:

I - bibliotecas públicas e privadas;

II - bibliotecas de entidades não governamentais;

III - entidades relacionadas ao livro, à leitura e à literatura;

IV - profissionais e pesquisadores de áreas afins; e

$V$ - outros que, por sua identidade, se relacionem com o Sistema Municipal de Bibliotecas, Livro, Leitura e Literatura.

Art. 71. Fica criado o Sistema de Bibliotecas Públicas do Município de Londrina (SBPML), composto por:

I - Biblioteca Pública Municipal Prof. Pedro Viriato Parigot de Souza, considerada unidade sede para o sistema de bibliotecas do Município;

II - Biblioteca Ramal Vila Nova;

III - Biblioteca Ramal Lupércio Luppi, instalada no Centro Cultural da Região Norte;

IV - Biblioteca Especializada do Museu de Arte de Londrina;

V - Biblioteca Especializada do Professor;

VI - Bibliotecas Escolares Municipais;

VII - Biblioteca Especializada Infantil; e

VIII - outras que vierem a ser criadas.

Art. 72. A gestão do Sistema Municipal de Bibliotecas do Município de Londrina (SBPML) compete à Secretaria Municipal de Cultura e à sua respectiva Diretoria de Bibliotecas.

Art. 73. As bibliotecas integrantes do Sistema de Bibliotecas Públicas do Município de Londrina (SBPML) estarão interligadas em rede, o que oportunizará ao usuário usufruir do acervo de qualquer região da cidade e terá por objetivos gerais:

I - definir diretrizes gerais de orientação para o cumprimento dos objetivos do sistema de bibliotecas públicas do município de Londrina (SBPM); 
II - estabelecer critérios de identidade baseados no papel e na função das bibliotecas do SBPML junto à comunidade em que atua;

III - propor e divulgar padrões e procedimentos técnicos que sirvam de orientação aos gestores das bibliotecas do SBPML;

IV - possibilitar meios de formação, treinamento, assistência técnica e consultoria às entidades participantes do SBPML, de acordo com as necessidades e também nos aspectos relacionados à adequação, fusão e reformulação de bibliotecas;

$\mathrm{V}$ - proporcionar meios para o desenvolvimento de programas de incremento, melhoria e atualização de recursos humanos, visando ao aprimoramento do desempenho das bibliotecas;

$\mathrm{VI}$ - estimular propostas de realização de atividades culturais e educativas das bibliotecas do SBPML junto às comunidades;

VII - articulação entre a preservação, conservação e ampliação do acervo bibliográfico com auxílio orçamentário do Município;

VIII - estimular a formação de leitores em todos os âmbitos do SBPML; IX - promover e estimular intercâmbio com outros centros de informação;

$X$ - incentivar a busca, a recuperação e o uso da informação; e

$\mathrm{XI}$ - promover a disseminação das obras de autores locais.

Art. 74. São também consideradas centros culturais para a realização de programação cultural as bibliotecas integrantes do Sistema de Bibliotecas Públicas do Município de Londrina (SBPML), a saber:

I - Biblioteca Pública Municipal Professor Pedro Viriato Parigot de Souza biblioteca sede do SBPML responsável pelas diretrizes gerais do Sistema;

II - Bibliotecas Ramais, as localizadas em bairros da cidade;

III - Bibliotecas Especializadas, as que têm acervo especializado, como as que pertencem a museus e teatros;

IV - Bibliotecas Escolares, as da Rede Municipal de Ensino de Londrina destinadas ao atendimento de estudantes da Educação Infantil e do Ensino Fundamental.

Art. 75. Todas as novas unidades que forem criadas após a publicação desta Lei serão automaticamente inseridas no Sistema de Bibliotecas Públicas do Município de Londrina. (LONDRINA, 2012).

Vale ressaltar que essa lei foi estruturada com base em discussões e proposições realizadas em conjunto entre a Diretoria de Bibliotecas, bibliotecários e funcionários das bibliotecas públicas de Londrina em consonância com a Secretaria Municipal de Cultura e as conferências municipais, de 2009 a 2011 quando Silva foi Diretor das Bibliotecas Públicas do Município de Londrina.

Essa é uma importante conquista para o Município de Londrina, pois essa lei assegura como Política Pública, tudo o que Silva havia se empenhado desde o início da década de 2000 para estruturar, sistematizar e firmar no Município de Londrina, o acesso à biblioteca, ao livro, à leitura e à literatura. 


\section{CONSIDERAÇÕES FINAIS}

No Município de Londrina, como em quase todo território brasileiro, as bibliotecas escolares encontraram muitas dificuldades para sua legitimação. Na década de 50 houve um aumento da população urbana de Londrina e a cidade sente a necessidade de melhorar sua infraestrutura aumentando o número de escolas e inicia então a reflexão sobre a importância das bibliotecas para incentivo à leitura e foi neste período que houve a instalação da primeira Biblioteca Pública Municipal de Londrina e começa aí a democratização do acesso à informação e à cultura.

No entanto, nas décadas de 50 e 60 do século XX, o Município de Londrina enfrenta uma grande crise no desenvolvimento do ensino, faltavam escolas e faltavam professores capacitados, faltava estruturação dos órgãos governamentais responsáveis pela Rede de Ensino. Assim, neste período, o foco foi à estruturação e consolidação do ensino e as bibliotecas escolares ainda estavam longe de se tornarem presentes dentro das escolas públicas do Município.

Nas décadas de 70 e 80 começaram a surgir as bibliotecas sucursais, ou seja, as bibliotecas escolares, que situavam dentro das Escolas Municipais, porém eram administradas pela Biblioteca Pública Municipal de Londrina. Aos poucos estas bibliotecas foram aumentando e ampliando o número de livros para acesso a comunidade escolar.

A década de 90 é encerrada com 56 bibliotecas escolares ou sucursais, espalhadas pelos bairros de Londrina, porém este equipamento não estava inserido no contexto pedagógico da escola e não atuava ativamente na promoção da leitura. Foi somente em 2000 pela implantação do projeto Palavras Andantes que as bibliotecas escolares começaram a ser valorizadas, estruturadas com ações sistematizadas de promoção a leitura ao livro a literatura, além de oferecer apoio pedagógico a professores e alunos.

Com o Palavras Andantes iniciou-se uma preocupação maior com a formação do leitor em Londrina e com a formação dos profissionais que atuavam nas bibliotecas das escolas, pois já se acreditava na importância destes espaços para formação de um leitor crítico e reflexivo. Neste período havia 79 escolas em Londrina e todas tinham uma biblioteca ou espaço com armários e livros.

Vale ressaltar que as bibliotecas escolares são equipamentos fundamentais no processo de formação do leitor autônomo, crítico e reflexivo, além de contribuir no 
processo de ensino-aprendizagem, como apoio didático aos educadores e às pesquisas dos educandos.

Nos dias atuais, Londrina caminha e tenta manter as conquistas do Palavras Andantes, porém ainda há muito o que se fazer para que as bibliotecas escolares no Município de Londrina exerçam seu papel. Houve avanços e garantias em Leis, mas é preciso avançar ainda mais para que as bibliotecas exerçam de fato sua e função no ambiente escolar.

\section{REFERÊNCIAS}

ASARI, A. Y.; TUMA, M. M. Aspectos Históricos, Físicos, Econômicos e Institucionais do Município de Londrina. Londrina : Prefeitura Municipal, 1978.

BONI, Paulo César. Fincando estacas! A história de Londrina (década de 30) em textos e imagens. Londrina: 2004.

BRASIL. Governo Federal. Lei n. 10.753 de 30 de outubro de 2003. Da Politica Nacional do Livro - Diretrizes Gerais. Disponível em:

<http://www.receita.fazenda.gov.br/Legislacao/leis/2003/lei10753.htm>. Acesso em: 20 fev. 2013.

BRASIL. Ministério da Educação. Avaliação de bibliotecas escolares no Brasil Brasília: Ministério da Educação, 2011.

BRASIL. Ministério da Cultura. Prêmio Viva Leitura 2008. Disponível em:

<http://www.premiovivaleitura.org.br/pdf/vivaLeitura2008.pdf>. Acesso em: 25 fev. 2013.

CANDOTTI, Eliane A. Memórias da cidade: Londrina 1930/1960. 1997. Monografia (Especialização em História) - Universidade Estadual de Londrina, Londrina, 1997.

CÉSAR, Zênite T. R. Estudo da evolução do ensino municipal de Londrina 19301970.1976. Tese (Livre Docência) - Universidade Federal do Paraná, Curitiba, 1976.

COUTINHO, Humberto Puiggari. Londrina 25 anos de sua história. São Paulo: gráfica universal, 1959.

FUNDAÇÃO UNIVERSIDADE ESTADUAL DE LONDRINA. Museu histórico Pe. Carlos Weiss. Boletim, Londrina, n. 6, 1980.

LONDRINA. Prefeitura Municipal. Biblioteca Pública de Londrina: 50 anos no coração da cidade. Londrina: Midiograf, 2001.

1971.

O que fizemos o que fazemos o que faremos. Sec. Ed. e Cultura, 
Londrina. Prefeitura Municipal. Bibliotecas Escolares. Disponível em:

$<$ http://www.londrina.pr.gov.br/index.php?option=com_content\&view=article\&id=232\&ltemi $\mathrm{d}=306$ > . Acesso em: 03 jan. 2013.

Biblioteca Infantil de Londrina. Disponível em:

<http://www.londrina.pr.gov.br/index.php?option=com_content\&view=article\&id=229\&ltemi $\mathrm{d}=304>$. Acesso em 12 fev. 2013.

Projeto Sócio pedagógico de novas diretrizes educacionais para o Município de Londrina. Curitiba, consulplan, 1969.

Sec. Ed. Cultura, 2013.

Relatório de atividades da Biblioteca Infantil de Londrina. Londrina:

Lei no 11.535, de 9 de abril de 2012. Dispõe sobre o Sistema Municipal de Cultura de Londrina, seus princípios, objetivos, estrutura, organização, gestão, interrelações entre os seus componentes, recursos humanos, financiamento e dá outras providências. Disponível em:

<http://www2.Iondrina.pr.gov.br/jornaloficial/images/stories/jornalOficial/jornal_1845_assin ado.pdf>. Acesso em: 5 abr. 2013.

PARANÁ. Governo do Estado. Secretaria de Estado de Educação. Ato Administrativo n. 282 de 2012. Londrina: NRE, 2012a.

- Governo do Estado. Secretaria de Estado de Educação. Pasta de

documentação escolar do Colégio Evaristo da Veiga. Londrina: NRE, 2012b.

SILVA, Rovilson José. A hora do conto na escola: paradoxos e desafios. Revista Terra e Cultura, Londrina, n. 43, ano 22, jul./dez, 2006a. Disponível em:

<http://web.unifil.br/docs/revista_eletronica/terra_cultura/n43/terra_07.pdf>. Acesso em: 5 abr. 2013.

Biblioteca escolar e a formação de leitores: o papel do mediador de leitura. Londrina: Eduel, 2010.

O professor mediador de leitura na biblioteca escolar da rede municipal de

Londrina: formação e atuação. 2006. 267 f. Tese (Doutorado em Educação) -

Universidade Estadual Paulista Júlio de Mesquita, Marília, 2006b. Disponível em:

<http://base.repositorio.unesp.br/handle/11449/101530>. Acesso em: 5 abr. 2014.

\section{Title}

History of School Libraries in Londrina

\section{Abstract}

Introduction: This article aims to present the history of school libraries in the city of Londrina, its 
development since its colonization to the present day.

Objective: The study aimed to describe and analyze the emergence of school libraries of process with in the education system and the structure of libraries in these spaces, evolution, achievements and progress.

Methodology: It is a bibliographic nature of research, based on the identification, reading and analysis of written documents, laws and decrees, which occurred over time in this city.

Results: Discusses the history of school libraries in the city of Londrina, as well as its policy of training of readers, in particular, through the Errant Words Project.

Conclusions: This institution, although it is currently guaranteed by law, still requires maturity and deeper reflections. The aim of this work to present the history of school libraries in Londrina and raise discussions and contributions for future studies on this theme.

Keywords: Schoollibrary. Londrina. Historiography.

\section{Título}

Historia de las bibliotecas escolares en Londrina

\section{Resumen}

Introducción: Este artículo tiene por objetivo presentar la historia de las bibliotecas escolares enlaciudad de Londrina, sudesarrollo desde lacolonización hasta nuestros dias.

Objectivos: La investigacion tuvo como objetivo describir y analizar la aparición de las bibliotecas escolares em lo sistema educativo y la estruturación de las bibliotecas em los espacios, evolución, los logros y el progreso.

Metodología: Es un carácter bibliográfico de investigación, basado em La identificación, lectura y análisis de documentos escritos, leyes y decretos que se produjo em el tiempo en esta ciudad.

Resultados: Aborda la descripción de la evolución histórica de las bibliotecas escolares en la ciudad de Londrina, así como su política de formación de lectores, en particular, a través del Proyecto Palabras Andantes.

Conclusiones: Esta instituición, aun que em la actualidad este garantizada por lãs leyes, todavia requiere madurez y reflexiones más profundas. Intenta-se con este trabajo presentar la histografia de las bibliotecas escolares en Londrina y elevar los debates y contribuiciones para los futuros estudios sobre este tema.

Palabras clave: Biblioteca escolar. Londrina. Historiografia.

Recebido em: 12.11 .2014

Aceito em: 22.12.2014 